\title{
Catolicismo e casamento civil na Cidade de Goiás: conflitos políticos e religiosos (1860-1920)*
}

\author{
Maria da Conceição Silva \\ Doutoranda em História/UNESP/Franca/SP
}

\section{Resumo}

Este artigo analisa a atuação do clero no sentido de normalizar o comportamento das pessoas por meio da celebração do matrimônio na cidade de Goiás, no período de 1860 a 1920, sendo que as normas católicas tinham por objetivo implantar um catolicismo ultramontano tridentino. Assim, o clero ultramontano procurava moralizar a vida privada do fiel e também evitar a adesão deste ao casamento civil, sobretudo após a aprovação do Decreto n. 181, de 24 de janeiro de 1890, que o estabeleceu no País.

Palavras-chave: Catolicismo. Casamento. Cidade de Goiás.

\begin{abstract}
This article analyses the performance of the clergy as a means to adjust the behavior of people by celebrating matrimonies in Goiás city in the period between 1860-1920. The catholic principles had the purpose of establishing a ultramontanist catolicism with Tridentine aspect. Therefore, the ultramontanist clergy aimed at moralizing the private lives of its devoters and at the same time avoid their adhension to civil marriage, especially after the approval of the Decret n. 181, from January $24^{\text {th }} 1890$, that has established it in the country.

Keywords: Catholicism. Marriage. Goiás city.
\end{abstract}

Analisar a temática catolicismo e nupcialidade na capital da província goiana — cidade de Goiás — é embrenhar-se nas entrelinhas de vasta documentação para entender o significado do casamento para a população, a maneira pela qual a Igreja disseminava os "bons costumes" por meio da celebração do sacramento do matrimônio, e quais os artifícios usados pelo clero ultramontano para repelir o casamento civil, aprovado em 1890. Para tanto é preciso considerar a importância dos conflitos que marcaram a história do Brasil na segunda metade do século XIX, entre clero ultramontano e parlamentares liberais. Estes, ao defenderem a modernização do País, reivindicavam a aprovação de projetos que suscitaram profícuos debates no Parlamento brasileiro. No entanto, a aspiração desses políticos era a de eliminar o amplo 
poder da Igreja Católica em assuntos como a liberdade de culto, o casamento civil e a extensão deste aos não-católicos (casamentos mistos), e também o sepultamento dos defuntos. Projetos que foram importantes para a transição da Monarquia à República, uma vez que eles foram aprovados no Parlamento e implantados no regime republicano.

A maioria dos embates entre os defensores de políticas liberais e os da Igreja encontra-se publicada nos anais do Parlamento brasileiro e nos jornais católicos e civis do período. Portanto, estamos convencidos de que a compreensão da temática nupcialidade insere-se também na problemática religiosa, sobretudo porque o projeto de casamento civil foi longamente debatido juntamente com o da liberdade de culto e o da secularização dos cemitérios, incorporados com propostas do liberalismo europeu.

Neste sentido, a análise do catolicismo e da nupcialidade na cidade de Goiás nos conduz a avaliar a importância dos projetos apresentados no Parlamento, com o objetivo de modernização do País, cuja proposta distanciava o homem do mundo visto apenas na perspectiva da moral cristã. Se o projeto católico aprovado pelos participantes do Concílio Vaticano I (1869-1870) era o de reprimir o liberalismo, de fato ele não se incorporaria à proposta defendida pelos políticos que desejavam implantar no País o progresso.

124 De modo geral, a Igreja Católica, ao condenar tudo que se associasse ao liberalismo, optou pela implantação do catolicismo ultramontano de "inspiração romana, eclesial e sacramental",' cuja finalidade era legitimar as propostas do clero conservador. Assim, a história da "Igreja é neste período fundamentalmente "conservadora". Toda uma atitude de reação contra o liberalismo, que culmina no Syllabus e no Vaticano I, [foi] transferida para o Brasil”". A Igreja brasileira, ao adotar a linha de romanização conservadora, numa perspectiva marcada pelo centralismo institucional em Roma, estaria optando por um projeto em que os seus representantes frontalmente iriam debater-se com os protagonistas do liberalismo no País, seja em âmbito nacional e/ou regional, a exemplo do que se deu na capital goiana após a Proclamação da República.

Estudiosos do catolicismo, entre os quais destacam historiadores e pesquisadores ${ }^{3}$, têm se dedicado à compreensão das tendências católicas, notadamente a ultramontana, procurando mostrar os embates ocorridos no Brasil na segunda metade do século XIX. Assim, David Gueiros Vieira afirma que o "ultramontanismo do século XIX colocou-se não apenas numa posição a favor de uma maior concentração do poder eclesiástico nas mãos do papado, mas também contra uma série de coisas que eram consideradas erradas e perigosas para a Igreja". Para Ivan Aparecido Manoel, o catolicismo ultramontano foi 
(...) muito mais do que um conjunto de teorias e ações, ele foi uma intenção, uma vontade da instituição católica de intervir no governo da polis para transformá-la efetivamente na Civitas Dei, e essa vontade de intervenção estava em consonância com as funções que a Igreja sempre se atribuiu e em harmonia com sua filosofia da história. Se a história humana é a história da sua salvação, cabe à Igreja, na qualidade de Mater et Magistra, e a mais ninguém, a tarefa de estabelecer os parâmetros do ordenamento social, de modo a não permitir que o Mal provoque a perdição definitiva do homem. ${ }^{5}$

Segundo Hugo Fragoso, havia um clero adepto da "orientação do Magistério da Igreja” ${ }^{\circ}$ em especial da política pontifícia de Pio IX, após a realização do Concílio Vaticano I. Nesta linha de interpretação, Maria Aparecida Gaêta mostra que:

(...) Os excessos do regalismo e do liberalismo, as medidas arbitrárias às liberdades da Igreja fizeram com que os homens ligados ao ultramontanismo se engajassem num movimento que visava salvar a Igreja das críticas e das práticas liberais, bem como apresentar um programa político fundado na doutrina e na hierarquia eclesiástica. E com essa autoconsciência, exacerbada pela contestação dos liberais e dos protestantes que paulatinamente iam se inserindo no contexto nacional, o episcopado brasileiro sustentou que só a verdade (católica) e não o erro (liberal e/ou protestante) tinha direito de existência e de divulgação. ${ }^{7}$

Na concepção dos liberais, o poder da Igreja Católica no Brasil do Segundo Império, concebido sob padroado régio e afiançado pelo episcopado defensor da romanização conservadora, deveria ser suprimido para propiciar a implantação das suas propostas modernizadoras. E minimizar as possibilidades de domínio dos católicos ultramontanos seria evitar também a candidatura de seus representantes a cargos políticos. É congruente a afirmativa de José Murilo de Carvalho ao dizer que no ano de "1875, por exemplo, vigários e bispos, que no Império eram também funcionários públicos, foram impedidos de se candidatar em suas próprias paróquias e bispados"». Tal fato corrobora os acontecimentos que se iniciaram em 1872, com seu ápice na "História da Questão Religiosa”, indo bem além desta. Antonio Carlos Villaça ressalta que:

Toda Questão entre bispos e governo é afirmar-se ou não a necessidade do placet para as bulas pontifícias.

A problemática da Questão Religiosa não se esgota com a Questão, 1872/75. Vem de antes. Sobreviverá à Questão. Quem acompanha os debates parlamenta- 
res posteriores à Questão, ao longo da década, logo percebe que a Questão não se restringe ao processo judiciário. ${ }^{9}$

Nos dizeres de Vilaça, o incidente com a maçonaria não foi a única razão para as prisões de D. Vital Maria Gonçalves de Oliveira e D. Antônio de Macedo Costa. Os bispos foram além nas suas ações para fazerem valer a proposta conservadora que defendiam. Por isto, não se intimidaram ao interceptar ordens contrárias nas suas dioceses. Assim, ressaltar a "inelegibilidade dos padres” é considerar todas estas questões que envolveram a Igreja e os políticos liberais. Tempos depois, os padres perderiam seus espaços de atuação nas câmaras estaduais e nacional.

Não há como dissociar catolicismo e casamento, particularmente ao investigá-los no contexto do Brasil do Segundo Império, uma vez que a Igreja detinha o poder legal sobre o matrimônio, fazendo valer as regras tridentinas e depois as do Direito Canônico. Estabelecia-se que o "ato jurídico válido está intrinsecamente no sacramento: é o próprio sacramento" ${ }^{10}$. Por esta razão, a Igreja também seria responsável quanto a combater as uniões ilegítimas, o que já fazia desde o século XVIII, quando os padres se encarregavam das desobrigas.

126 A cidade de Goiás, capital da província e depois do Estado, onde as notícias chegavam tardiamente, não permaneceu apática ao que acontecia nas demais províncias do País, sobretudo no Rio de Janeiro e em São Paulo. Assim, a análise da temática catolicismo e casamento nos propicia entender a conturbada história que ali se desencadeara entre eclesiásticos ultramontanos e políticos liberais liderados pela oligarquia dos Bulhões. A capital goiana foi palco das idéias liberais introduzidas por esses jovens que estudaram Ciências Políticas e Direito em São Paulo. A família dos Bulhões, constituída de intelectuais, tinha compreensão do que representavam as propostas do Partido Liberal para Goiás. Vale ressaltar que, mais tarde, os arranjos políticos e as alianças matrimoniais os favoreceram para galgar um espaço no Partido Republicano. À frente deste partido estava o líder do movimento republicano goiano Joaquim Xavier de Guimarães Natal, formado em Direito em São Paulo, casado com Ângela de Bulhões, irmã de José Leopoldo de Bulhões Jardim. Sendo eles os promotores de concepções modernizadoras na capital, ${ }^{11}$ na segunda metade do século XIX, empenharam-se pela "liberdade de culto, secularização dos cemitérios, registros e casamento civil", ${ }^{12}$ confrontando-se com a linha religiosa adotada pelos bispos que conduziram a diocese até o ano de 1896. A partir do bispado de D. Joaquim Gonçalves de Azevedo (1865-1876), ${ }^{13}$ depois com D. Cláudio José Gonçalves Ponce de Leão (1881-1890), e por último com D. Eduardo Duarte e Silva (1891-1908), o ultramonismo foi a li- 
nha de trabalho seguida por eles. No bispado de D. Prudêncio Gomes da Silva (1908-1922), a conjuntura histórica não mais propiciara espaço para o exercício religioso ultramontano de antes. Mas todos eles mostraram-se zelosos dos seus "rebanhos". Conclamaram os vigários e membros da Igreja e os goianos em geral a observarem a doutrina cristã, considerando a importância da administração dos sacramentos, especialmente o do matrimônio. Seu objetivo era evitar que a população vivesse em estado de pecado como, digamos, a mancebia, ou aderisse ao casamento civil, considerado concubinato.

O teor da política ultramontana em Goiás pode ser observado, por exemplo, na carta pastoral de D. Cláudio José Gonçalves Ponce de Leão:

(...) O Sacramento do Matrimônio deve ser tratado de modo muito diverso do que se tem feito; dando-se as bençãos intra missam, e recebendo o consentimento dos noivos immediatamente antes d'essa missa; devem ser publicados os trez proclamas, bem examinados os noivos, seos parentes e outras pessoas, que conheçáo os impedimentos; os parochos devem ajudar seos frequezes na redação das petições de dispensa, indicando as razões valiosas existentes para ser concedidas as dispensas; podem os parochos accostumar seos frequeses de sorte que os noivos sejáo sempre sujeitos ao exame de doutrina. Os livros de assentos de baptisados, casamentos e obitos devem andar sempre em dia, preparados e redigidos de tal sorte, que possão as certidões d'elles tirados servir de documentos legaes. Cada um pois vá estudando seriamente o ritual, e examinando as dificuldades, que encontra para serem ellas resolvidas. ${ }^{14}$

Neste ponto, a freqüência aos sacramentos seria fundamental para a manutenção das regras como estabeleciam as Constituições Primeiras do Arcebispado da Bahia, aprovadas em 1707, recomendadas em seus escritos pastorais.

Foi o bispado de D. Eduardo Duarte e Silva (1891-1908) que marcou um período de latentes conflitos na história local entre grupos políticos liderados pelos Bulhões. O bispo era um ultramontano convicto - realizara seus estudos teológicos em Roma - uma das razões de ser o defensor do catolicismo romanizado em sua diocese. E debateu-se frontalmente com os membros do antigo Partido Liberal na capital. Ronaldo Vaz atesta: "Na oligarquia dos $\mathrm{Bu}-$ lhões a Igreja encontrou o seu principal adversário em Goiás. Os Bulhões foram, aliás, os condutores de quase todos os movimentos de modernização que ocorreram em Goiás, a exemplo do que acontecia no Brasil."15

A vitória dos Bulhões iniciou-se em 1878, com a indicação de Luiz Augusto Crespo (22-7-1878 a 18-3-1879) como presidente da Província. A sua ligação com Augusto Fleury, inimigo dos jovens Bulhões, proporcionou o 
rompimento de Leopoldo de Bulhões com o presidente do Estado. Foi com Aristides de Souza Spínola (15-3-1878 a 1-2-1881) que a família Bulhões encontrou apoio político para afirmar-se no poder regional até 1912, quando ocorreu a derrocada desta oligarquia em conseqüência de desentendimentos com os Jardins e Caiados e pelo apoio de Hermes da Fonseca a estes, cujo baluarte político passou a ser a oligarquia caiadista até a década de $1930 .{ }^{16}$

Com a Proclamação da República, os Bulhões, antigos liberais, não perderam tempo para se fortalecer tanto regional como nacionalmente, o que, por sua vez, iria assinalar ser esse um momento de dificuldades políticas para a Igreja ultramontana no Estado. Este fato fez D. Eduardo Duarte e Silva sentir exaurir todas as possibilidades de manutenção das suas propostas, inclusive as do Partido Católico em Goiás — fundado em 20 de julho de 1890 — sob a liderança do clero conservador. A proposta deste partido assentava-se na luta para a revogação dos decretos de separação da Igreja e do casamento civil. As eleições de 20 de maio de 1895 confirmaram tanto o prestígio como o fortalecimento dos Bulhões na esfera nacional pelos arranjos políticos e também pelas alianças matrimoniais que os favoreciam. Deste modo, execravam-se todas as pretensões do Partido Católico goiano no sentido de combater as reformas advindas da República, como a separação da Igreja e a "imoralidade" do casamento civil. ${ }^{17}$ Não havia outra alternativa a D. Eduardo e a seus aliados a não ser ausentarem-se da capital. Assim, foi efetivada a transferência da sede episcopal da cidade de Goiás para Uberaba, no Triângulo Mineiro, em 1896, endossada pelo pontífice Leão XIII. Há quem mostre essa mudança episcopal como decorrência do incidente com a maçonaria, ${ }^{18}$ regulamentada em Goiás em 1865. Não resta dúvida de que os Bulhões eram também maçons. Afinal, esta irmandade exercia seu poder em todas as regiões do País, e Goiás não ficou isenta de sua influência.

O conflito entre os Bulhões e o bispo D. Eduardo Duarte e Silva é investigado por Ronaldo Vaz, que o mostra inserido no contexto político de perda de prestígio de D. Eduardo na Igreja, sobretudo após o malogro do Partido Católico na capital goiana. Há implicações mais profundas que não se reduzem apenas à política do bispo ultramontano e ao partido por ele defendido em Goiás, mas sim a adoção de uma política religiosa que perdera seu campo de atuação em todo o País. Com a aprovação dos projetos debatidos no Parlamento por vários anos, que resultaram na separação entre Igreja e Estado e na aprovação do casamento civil, estes foram alvos de luta de todo o episcopado brasileiro, sendo a não aplicação do decreto de separação e do casamento no cotidiano local fatos irreversíveis no desenrolar da história política e social do País. 
As formalidades do casamento civil foram discutidas e aprovadas pela comissão constituinte em 2 de setembro de 1891. Desta forma, a Igreja foi apresentada em condições secundárias perante o Estado e a constituição da família.

Antes da aprovação do Decreto n. 181, em 24 de janeiro de 1890, sem dúvida que o casamento religioso na cidade de Goiás era um mecanismo propiciador de arranjos políticos e preservador dos interesses familiares, habitual em todo o Brasil Império. Além dos interesses políticos, o matrimônio havia adquirido seu significado para a população. O recebimento deste sacramento e da bênção aos nubentes era sinônimo de união conjugal normal. Deste modo, os nubentes evitavam viver em estado de pecado. Daí, o casal poderia constituir família e ter o reconhecimento social, como ressalta Sheila Faria em pesquisa sobre Campos dos Goitacazes. ${ }^{19}$ De fato, o matrimônio era desejo, e provavelmente o costume de todos quando as condições socioeconômicas permitiam. Segundo as regras da Igreja, casar representava adesão a um dos mais importantes sacramentos cristãos.

Neste sentido, Ilmar Rohloff de Mattos, estudando a formação do Estado imperial, enfatizou que "seria por meio dos casamentos (...) que se estabeleceriam sólidas e frutuosas relações entre as grandes famílias, preocupadas em preservar os monopólios que as distinguiam, e os elementos que as representavam, e a quem caberia ordenar esses mesmos monopólios. ${ }^{20}$ " Para a capital goiana, caberia aos ex-liberais do clã bulhônico a efetivação dos projetos de modernização aprovados no Parlamento brasileiro. No entanto, "ordenar o monopólio" foi muito mais uma ação política de manutenção do poder que não significou um avanço modernizador para a capital, e muito menos para todo o Estado de Goiás. Mas o casamento civil foi instituído a partir do Decreto 181, fosse ele princípio modernizador ou não para o Estado.

Nos livros de registros de casamento religioso, ${ }^{21}$ de 1860 a 1920, das paróquias de Sant'Anna e Carmo da cidade de Goiás, tem-se a impressão de que faltam registros de matrimônios, uma vez que são constatadas anotações de alguns casamentos fora de ordem cronológica e também dados incompletos. Em visita pastoral às freguesias de S. Anna e Carmo da capital de Goyaz, em 9 de janeiro de 1901, D. Eduardo Duarte e Silva, supervisionando as anotações do livro $6,^{22}$ chamou a atenção do vigário pelas informações incompletas dos casamentos. É possível notar que em alguns livros existem sentenças de pessoas casadas solicitando ao vigário que fizesse os assentos de seus matrimônios, por não tê-los encontrado em nenhum dos livros da paróquia. Apesar da possibilidade de haver sub-registros, os dados parecem mostrar tendências claras de adesão a partir de determinado período (ver Tabela 1). 
Tabela 1

Períodos de casamento religioso, cidade de Goiás, 1860-1920

\begin{tabular}{|c|c|c|c|c|c|c|c|c|c|c|c|c|c|c|}
\hline \multirow[t]{2}{*}{ Períodos } & \multicolumn{13}{|c|}{ Meses } & \multirow[t]{2}{*}{ Total } \\
\hline & jan. & fev. & mar. & abr. & maio & jun. & jul. & ago. & set. & out. & nov. & dez. & $\begin{array}{c}\text { Média } \\
\text { anual de } \\
\text { casamentos }\end{array}$ & \\
\hline $1860-61$ & 7 & 10 & 1 & 3 & 6 & 8 & 2 & 5 & 3 & 1 & 3 & 4 & 26,5 & 53 \\
\hline $1862-63$ & 4 & 3 & 3 & 3 & 3 & 7 & 2 & 5 & 5 & 2 & 11 & 2 & 25 & 50 \\
\hline $1864-65$ & 8 & 9 & 3 & 3 & 9 & 5 & 5 & 4 & 2 & 9 & 10 & 3 & 35 & 70 \\
\hline $1866-67$ & 1 & 8 & 3 & 7 & 6 & 7 & 1 & 2 & 1 & 4 & 3 & 3 & 23 & 46 \\
\hline $1868-69$ & 8 & 8 & 1 & 3 & 10 & 29 & 3 & 4 & 3 & 7 & 15 & 1 & 43,5 & 87 \\
\hline $1870-71$ & 6 & 10 & 4 & 2 & 13 & 12 & 10 & 4 & 8 & 5 & 3 & 3 & 40 & 80 \\
\hline $1872-73$ & 11 & 3 & - & 6 & 6 & 4 & 5 & 6 & 4 & 7 & 3 & 2 & 28,5 & 57 \\
\hline $1874-75$ & 9 & 8 & 1 & 6 & 5 & 11 & 4 & 7 & 6 & 10 & 4 & 3 & 37 & 74 \\
\hline $1876-77$ & 5 & 4 & - & 2 & 3 & 9 & 3 & 3 & - & 1 & 4 & 3 & 18,5 & 37 \\
\hline $1878-79$ & 2 & 5 & 3 & 3 & - & 6 & 3 & 2 & 10 & 2 & 8 & 4 & 24 & 48 \\
\hline $1880-81$ & 2 & 6 & 5 & 4 & 7 & 6 & 6 & 8 & 4 & 8 & 11 & 10 & 38,5 & 77 \\
\hline $1882-8$ & 3 & 10 & 1 & 4 & 5 & 6 & 7 & 4 & 9 & 42 & 4 & 1 & 48 & 96 \\
\hline $1884-85$ & 5 & 17 & 1 & 3 & 9 & 6 & 5 & 3 & 7 & 5 & 7 & 2 & 35 & 70 \\
\hline $1886-87$ & 9 & 13 & 4 & 11 & 12 & 13 & 18 & 17 & 8 & 16 & 13 & 5 & 69,5 & 139 \\
\hline $1888-89$ & 21 & 34 & 15 & 10 & 13 & 15 & 13 & 14 & 9 & 7 & 11 & - & 81 & 162 \\
\hline $1890-91$ & 4 & 16 & 1 & 17 & 19 & 4 & 1 & 4 & 2 & 6 & 6 & 8 & 44 & 88 \\
\hline $1892-93$ & 3 & 6 & 5 & 6 & 13 & 6 & 10 & 5 & 7 & 9 & 8 & 4 & 41,5 & 83 \\
\hline 1894-95 & 7 & 7 & 2 & 8 & 4 & 14 & 6 & 2 & 7 & 2 & 2 & 4 & 32,5 & 65 \\
\hline $1896-97$ & - & - & - & - & - & - & - & 1 & - & - & 3 & - & 2 & 4 \\
\hline $1898-99$ & 3 & 1 & 5 & 1 & 3 & 3 & 10 & 2 & 4 & 8 & 7 & 6 & 26,5 & 53 \\
\hline $1900-01$ & 4 & 13 & 1 & 1 & 4 & 6 & 3 & 9 & 8 & 2 & 2 & 7 & 30 & 60 \\
\hline $1902-03$ & 7 & 5 & - & 2 & 5 & 7 & 3 & 5 & 4 & 4 & 1 & 7 & 25 & 50 \\
\hline 1904-05 & 6 & 2 & 5 & 8 & 8 & 6 & 3 & 5 & 8 & 11 & 4 & 4 & 35 & 70 \\
\hline $1906-07$ & 9 & 5 & 6 & 5 & 4 & 5 & 3 & 9 & 9 & 5 & 7 & 2 & 34,5 & 69 \\
\hline 1908-09 & 7 & 9 & 11 & 3 & 8 & 8 & 11 & 5 & 7 & 9 & 8 & 7 & 46,5 & 93 \\
\hline $1910-11$ & 6 & 8 & 5 & 8 & 11 & 11 & 8 & 2 & 10 & 12 & 11 & 12 & 52 & 104 \\
\hline $1912-13$ & 3 & 7 & 1 & 3 & 8 & 10 & 6 & 4 & 11 & 9 & 7 & 12 & 40,5 & 81 \\
\hline 1914-15 & 5 & 9 & 3 & 7 & 11 & 12 & 6 & 6 & 14 & 9 & 8 & 13 & 51,5 & 103 \\
\hline $1916-17$ & 6 & 6 & 7 & 7 & 4 & 6 & 3 & 2 & 9 & 3 & 9 & 12 & 37 & 74 \\
\hline 1918-19 & 4 & 6 & 7 & 2 & 6 & 10 & 8 & 4 & 6 & 5 & 6 & 8 & 36 & 72 \\
\hline 1920 & 1 & 1 & 1 & - & 4 & 7 & 1 & 2 & 2 & 3 & 3 & 3 & 14 & 28 \\
\hline TOTAL & 176 & 244 & 105 & 148 & 219 & 259 & 169 & 155 & 187 & 223 & 202 & 155 & 37,3 & 2242 \\
\hline
\end{tabular}

Fonte: Livros 1, 2, 4, 5, 6, 7, 8 e 10 de registros de casamento da paróquia de Sant'Anna - Diocese da cidade de Goiás. 
Na Tabela 1 pode-se observar que há um acréscimo no número de casamentos a partir de 1868, possivelmente em razão de duas questões: a primeira, pela aplicação das propostas ultramontanas, uma vez que a celebração dos sacramentos era um dos seus objetivos. Tentava-se impedir que um homem e uma mulher vivessem amancebados, sem o recebimento do sacramento do matrimônio e dos demais sacramentos. A segunda questão: os padres ultramontanos, na capital goiana, tinham conhecimento do projeto de casamento civil que tramitava no Parlamento Brasileiro. Sendo contrários à aprovação do mesmo, procuravam mostrar à população a importância de se receber o sacramento do matrimônio. Vale ressaltar que: "A Igreja toma medidas preventivas, misericordiosas e vingadoras para proteger e affirmar a veneravel instituição do matrimonio." ${ }^{23}$ Parece que isto ocorreu em todas as regiões do País, como mostram as publicações em jornais e revistas do período e, em especial, no jornal católico O Apóstolo. Este jornal era um instrumento de divulgação dos ideais ultramontanos na capital federal.

Frei Gil Vilanova, chegando em Goiás, como conservador foi um defensor desse sacramento e, neste sentido, empreendeu esforços para que os católicos procurassem se casar.

Na cidade de Goiás, munido de poderes para celebrar casamentos sem pregão e sem impedimentos, e em qualquer Igreja, Frei Gil relaciona os casais que viviam maritalmente e os convocou afirmando: "É preciso que se casem! — Não? Então é preciso que se separem." Sua campanha surtiu efeito, pois num só dia, na primeira missa do Rosário, fez sete casamentos. No entanto, quando passava nas ruas o povo gracejava "Ou casa, ou separa. ${ }^{24}$ "

A atitude dos padres conservadores também pode ser observada no trabalho dos bispos goianos, especialmente entre os anos de 1890 e 1900, em suas visitas pastorais tanto à paróquia de Sant'Anna da cidade de Goiás quanto às demais da Província. Assim, o bispo Cláudio José Gonçalves Ponce de Leão, em pastoral à sua diocese, fez a celebração de casamentos para evitar que as pessoas continuassem em estado de pecado.

(...) Para dar-vos uma pequena ideia dos males, das cruéis enfermidades, que assolavam as freguezias visitadas, bastará dizer-vos que no anno de 1882 celebrarão-se mais de quatrocentos casamentos, e no anno de 1883 mais de mil, quasi todos de concubinarios; apezar de trabalharmos incessantemente, e talvez com excesso, raramente temos podido satisfazer a todos.... ${ }^{25}$

Para a análise da nupcialidade na cidade de Goiás, é pertinente a afirma- 
tiva de Alan Macfarlane de que "nas sociedades rurais, sobretudo, o casamento se baseia em grande medida nos interesses familiares e de grupo, não importando os sentimentos pessoais dos noivos, geralmente muito jovens". ${ }^{26}$ Os nubentes que se casaram no religioso ${ }^{27}$ na capital goiana, no período de 1860 a 1920, estavam em maior número numa faixa entre 21-30, e depois, aos 3140 anos de idade para os homens. As mulheres, entre os 15-20 e também entre os 21-30 anos. Casar nestas faixas de idade não significava que os noivos fossem "muito jovens" (ver Tabela 2).

Tabela 2

Idades de casamento de homens e mulheres, cidade de Goiás, 1860 - 1920.

\begin{tabular}{lrrrrr}
\hline $\begin{array}{l}\text { Faixas etárias } \\
\text { dos nubentes }\end{array}$ & $\mathbf{n}^{\mathbf{0}}$ noivos & \% noivos & $\mathbf{n}^{\mathbf{0}}$ noivas & \% noivas & Total \\
\hline $11-14$ & - & - & 38 & 3,7 & 38 \\
\hline $15-20$ & 88 & 8,4 & 484 & 47,2 & 572 \\
\hline $21-30$ & 611 & 58,4 & 364 & 35,5 & 975 \\
\hline $31-40$ & 207 & 19,8 & 100 & 9,7 & 307 \\
\hline $41-50$ & 83 & 7,9 & 30 & 2,9 & 113 \\
\hline $51-60$ & 33 & 3,2 & 7 & 0,7 & 40 \\
\hline $61-70$ & 21 & 2,0 & 3 & 0,3 & 24 \\
\hline $71-83$ & 3 & 0,3 & - & - & 3 \\
\hline Total & 1046 & 100 & 1026 & 100 & 2072 \\
\hline
\end{tabular}

Obs: Foram excluídos 1.200 noivos e 1.220 noivas para os quais não há indicação de idade.

Fonte: Livros 1, 2, 4, 5, 6, 7, 8 e 10 de registros de casamento da paróquia de Sant'Anna - Diocese da cidade de Goiás.

A respeito do que Macfarlane afirma sobre os "interesses familiares e de grupo", de fato, "casamentos endogâmicos” foram freqüentes entre famílias goianas como, por exemplo, os que ocorreram na família Bulhões-Jardim. Quase todos os membros desta família, e também de outras que comandaram o poder político no Estado, contraíram núpcias no mesmo clã. Famílias como a dos Bulhões, cujo tronco tem ascendência no século XVIII, acabaram tornando-se detentoras do poder político regional ou até mesmo nacional, 
como José Leopoldo de Bulhões Jardim, que foi constituinte em 1891 e ministro da Fazenda por duas vezes. Este contraiu matrimônio com sua sobrinha, Cecília Felix de Souza.

Maria Augusta Sant'Anna de Moraes, ao investigar o domínio da oligarquia bulhônica como portadora das propostas liberais em Goiás, não deixou de evidenciar as estratégias políticas sedimentadas pelos enlaces matrimoniais das famílias Soares de Bulhões, Farinha, Félix de Souza, Ludovico de Almeida e Rodrigues Jardim..$^{28} \mathrm{O}$ autor goiano Jarbas Jayme ressalta também a história dos matrimônios da família Bulhões dentro do mesmo clã. ${ }^{29}$

Neste sentido, Heliane Prudente Nunes, em pesquisa sobre famílias no Brasil e em Goiás, diz que:

(...) também em Goiás o conceito de casamento subordinava o indivíduo aos interesses das famílias; as asas do cupido estavam amarradas pelas limitações sociais. Até o final do século XIX, a maioria dos casamentos realizados, nas classes sociais mais abastadas, representa mais um contrato de política e de fortalecimento dos grupos de parentesco do que uma intenção amorosa. Casamentos entre parentes eram ideais porque garantiam a preservação do status e dos bens econômicos numa sociedade cheia de etnias misturadas e de aventureiros. ${ }^{30}$

De fato, o interesse de algumas famílias foi uma regra social vivenciada pela população da cidade de Goiás, sobretudo entre grupos que comandaram a política goiana. Provavelmente, casar no mesmo grupo familiar foi a maneira conveniente para manter os interesses entre iguais e entre famílias de prestígio político regional, antes e depois do casamento civil.

O controle das uniões nupciais por parte da Igreja acabou direcionando-se para o lado da conveniência. As normas do sacramento do matrimônio entre pessoas com grau de parentesco, tanto consangüíneo quanto por afinidade, acabaram sendo vistas como normais. No entanto, algumas regras deveriam ser obedecidas, como a da solicitação pelos nubentes dos banhos canônicos e da dispensa de impedimento quando havia. O bispo autorizava, em consonância com as normas estabelecidas pelas Constituições Primeiras do Arcebispado da Bahia de 1707,13 a dispensa do impedimento em grau de consangüinidade e outros que pudessem haver para a não-realização do casamento. Neste sentido, Maria Beatriz Nizza da Silva ressalta que:

(...) pela bula Magnam Profecto Curam, expedida em Roma a 26 de janeiro de 1790, o papa Pio VI concedeu aos bispos do Brasil o poder de dispensar gratuitamente em todos os graus de parentesco (à exceção do primeiro de consangüi- 
nidade, quer em linha direta, quer em linha transversal, e o primeiro de afinidade em linha reta apenas). ${ }^{32}$

Nos livros de registros de casamentos pertencentes às paróquias de Sant'Anna e Carmo da cidade de Goiás, os contraentes sempre obtinham a dispensa do impedimento que solicitavam ao bispo. As dispensas mais comuns foram de consangüinidade de $2^{\circ}$ grau igual, das linhas transversal e colateral. O número de dispensas de impedimentos consangüíneos e de afinidade concedidas pelos bispos goianos parece não ter sido tão grande assim (ver Tabela 3).

Tabela 3

Dispensas de impedimentos consangüíneos, cidade de Goiás, 1860 -1920

\begin{tabular}{lcc}
\hline Ano do casamento & $\mathrm{n}^{\mathbf{0}}$ de dispensas & Média anual de dispensas \\
\hline $1860-1870$ & 18 & 1,6 \\
\hline $1871-1880$ & 26 & 2,6 \\
\hline $1881-890$ & 21 & 2,1 \\
\hline $1891-1900$ & 9 & 0,9 \\
\hline $1901-1910$ & 8 & 0,8 \\
\hline $1911-1920$ & 31 & 3,1 \\
\hline Total & 113 & 1,8 \\
\hline
\end{tabular}

Fonte: Livros n. 1, 2, 4, 5, 6, 7, 8 e 10, registros de casamento religioso da paróquia de Sant'Anna - Diocese da cidade de Goiás.

É interessante notar que a capital goiana no século XX apresentou número significativo de deficientes mentais conhecidos por bobos. Em quase todos os lares havia um deficiente. Algumas pessoas são convictas de que a quantidade de indivíduos com problemas mentais foi uma conseqüência de casamentos dentro do mesmo grupo de parentesco. No entanto, a deficiência, seja física ou mental, não pode estar associada aos "casamentos endogâmicos" ${ }^{33}$ pois o número de dispensas de consangüinidade não foi tão alto. Seguramente, não houve uma alta proporção de casamentos entre parentes, pelo menos os legitimados pela Igreja Católica e anotados nos registros dos livros paroquiais.

Eni de Mesquita Samara enfatizou que "A vida urbana, durante o século 
XIX, possibilitou provavelmente a reunião mais freqüente dos membros de uma mesma família e, em decorrência, ao invés de produzir enfraquecimento das relações familiares reforçou — as pela maior assiduidade de vistas e proximidades." ${ }^{34}$ É possível que a premissa seja congruente com o cotidiano da cidade de Goiás, porque se por um lado havia uma considerável relação de proximidade entre as pessoas goianas, por outro prevaleciam interesses políticos e econômicos, como se comprova pela repetição de nomes de pessoas que foram testemunhas tanto no religioso como no civil.

Se os princípios celebrados pelos representantes da Igreja Católica eram de disseminar os bons costumes entre a população, tornam-se pertinentes algumas considerações sobre o comportamento moral dos fiéis e também do clero na capital de Goiás. Às vezes, as regras da doutrina cristã eram ignoradas por membros da própria Igreja, que certamente não as cumpriam com tanta eficiência.

Viajantes ${ }^{35}$ e cronistas que estiveram na cidade de Goiás, no século XIX, perceberam a falta de casamentos e afirmaram que havia um "concubinato generalizado" na cidade. O viajante Saint-Hilaire ${ }^{36}$ esteve na capital goiana em 1819, e emitiu algumas opiniões sobre o comportamento da população em geral, inclusive sobre a moral pública dos sacerdotes.

À procura de outras fontes documentais que pudessem oferecer possibilidades para comprovar a veracidade da afirmação do viajante europeu, vasculhamos documentos religiosos e leigos e, por fim, deparamo-nos com um óbito que nos chamou a atenção. Este constituiu um dado importante para que pudéssemos levantar hipóteses sobre a conduta moral dos membros da Igreja goiana, mas ainda permanece a indagação a respeito da ação dos bispos conservadores em relação ao comportamento desses padres. O óbito é de Antonio Candido de Azevedo, filho do monsenhor Joaquim Vicente de Azevedo: ${ }^{37}$

(...) Atesto que faleceu hontem a noite as 9 _ horas Antonio Candido de Azevedo, com 34 annos de idade, filho legitimo do falecido Monsenhor Joaquim Vicente de Azevedo sendo sua mãe Messias Xavier de Barros, de enfermidade, como febres, rheumatisma, e outras. Goyaz, 26 de dezembro de $1899 .{ }^{38}$

O teor do documento evidencia que havia dificuldade de alguns membros da Igreja em obedecer às regras católicas, fato ressaltado por Ida Lewcowicz ao pesquisar a fragilidade do celibato: "O concubinato, a mancebia e a ilegitimidade não foram incomuns no meio eclesiástico." ${ }^{39}$ Hugo Fragoso também aponta que "padres davam seu nome aos filhos, pois não eram eles simples 'bastardos', que só tivessem o sobrenome da mãe. Deviam ser criados os filhos em igualdade de condições com as melhores famílias do lugar." ${ }^{40} \mathrm{Como}$ 
se pode observar no atestado de óbito de Antonio Candido de Azevedo, este não era um simples "bastardo", sendo o seu pai Joaquim Vicente de Azevedo, portador do título de cônego (monsenhor) e também um influente membro do Club liberal ao lado dos "jovens Bulhões". ${ }^{41}$ Monsenhor Joaquim Vicente de Azevedo teve atuação esmerada e ocupou cargos importantes em Goiás. Sua posição política não condizia com a prática dos padres ultramontanos, que publicavam uma revista titulada: $A \mathrm{Cruz}^{42}$ Esta foi um instrumento de divulgação de suas ações conservadoras, mormente ao condenarem a liberdade de culto, a aprovação no Parlamento brasileiro de projetos como o da separação entre Igreja e Estado e o do casamento civil.

A aprovação do Decreto n. 181, de 24 de janeiro de 1890, instituindo o casamento civil, que logo seria regulamentado pelo governo provisório e previsto para entrar em vigor quatro meses depois, no dia 24 de maio de 1890, contribuiu significativamente para o processo de secularização que se consolidaria com a Constituição de 1891. Os padres consideraram o casamento civil como uma verdadeira afronta aos direitos dos católicos e um atentado à liberdade da sociedade. Casar no civil era visto como um atentado aos bons costumes da família cristã, e uma "mancebia legalizada".43

É importante salientar que no mesmo mês e ano em que ocorreu a apro136 vação do decreto de separação entre Igreja e Estado, houve também a aprovação do projeto de casamento civil. A finalidade deste era retirar poderes da Igreja Católica sobre a nupcialidade, vale dizer, muito mais sobre a família. Assim se expressaram os padres:

(...) Hontem era a separação da Egreja e do Estado e a secularização dos cemitérios; hoje é o casamento civil; amanhã será a lei do ensino falsamente chamado neutro, para que d' uma vez se acabe com Jesus Christo, e que o homem desterre á Deus da sociedade, da familia e até da alma dos meninos. ${ }^{44}$

O casamento civil — laico — provavelmente como opção, ou pelas condições econômicas e religiosas de parte da população do País e da capital goiana, atribuiu novo significado à família. O clero ultramontano exteriorizou sua inconformidade aos projetos dos liberais, sobretudo o do casamento civil, pois o consideravam como verdadeira depravação moral. Com esse intuito expressouse um membro da Igreja goiana, vigário da vila de Corumbá de Goiás:

(...) Começa a vigorar hoje no Brasil, a lei iníqua do casamento Civil (ou concubinato legal) que é sem dúvida o que há de mais ofensivo à consciência d'este povo-catholico em sua totalidade. Que não foi essa a aspiração nacional, provao o acrescido número de casamentos catholicos que tem sido feitos em todo Paiz, 
como lê-se em todos os jornais; - e isso unicamente porque ninguem quer o casamento civil.

Os pais tem razão de não quererem prostituir suas filhas. (Protesto de um Vigário. P. João Marques de Oliveira. Vila de Corumbá, 24 de maio de 1890).

Após a aprovação do Decreto n. 181, em 1890, a discussão a respeito da pertinência do casamento civil ainda continuou acirrada por parte do clero ultramontano. A posição clerical de repúdio à nova lei do casamento foi veiculada em jornais e revistas católicos nacionais e regionais, como no O Apóstolo e no O Lidador, e também nas homílias proferidas pelos padres e nos lembretes afixados nas matrizes. Exemplo de lembrete é o do vigário de Corumbá de Goiás, que em maio de 1890 afixou esta nota em sua matriz:

N.B. Os poderes humanos por mais déspotas que sejam, não podem impedir o casamento religioso. Quando a loucura [e] o despotismo dos que nos regem chegarem a seu cúmulo, iremos para as catacumbas, mas la mesmo administraremos os Sacramentos àqueles que no-los pedirem, desde que não haja impedimento por parte de nossa lei. (Junho-Continuam os casamentos religiosos, civil nem um.).

A nota expressava a posição e atitude dos padres conservadores que tentaram, sem sucesso, evitar a adesão dos goianos à lei do casamento civil. $\mathrm{O}$ bispo de Goiás, D. Eduardo Duarte e Silva, em portaria de 12 de outubro de 1891, enviada aos vigários de sua diocese, concordou com as prescrições dos bispos do Pará, Maranhão e do Rio Janeiro a respeito das normas do sacramento do matrimônio. Essas normas ainda eram o desdobramento das prescrições contidas nas Constituições Primeiras do Arcebispado da Bahia de 1707 e exaradas nas pastorais coletivas de 1890 e de 1900. O bispado goiano solicitava aos vigários que obedecessem às leis divinas ao celebrar o sacramento do matrimônio, pois o não-cumprimento dessas leis poderia resultar em pagamento de multas e prisões aos infratores. Neste sentido, a observância da doutrina cristã deveria ser o modelo para os bons costumes da família. As pessoas se interessaram em realizá-lo para regularizar sua situação conjugal perante a nova lei, conforme algumas anotações no livro n. 1 do Cartório Civil da cidade de Goiás. O direito da família foi contemplado mais tarde com a aprovação do Código Civil brasileiro em 1916.

Ainda serve de exemplo o diálogo entre marido e mulher publicado na revista A Cruz. Neste, como se pode observar, o clero demonstra desprezo e temor à nova lei de matrimônio: 
(...) Marido. - Já viste obstinação de moça? A nossa filha não quer ir ao escriptorio civil para preencher as formalidades legaes do seu casamento.

Mulher. - Faz ella muito bem.

Marido. - No entanto é necessario que a convenças a dar este passo, senão o casamento não surte os effeitos civis.

Mulher. - Deus me livre de aconselhar semelhante cousa á minha filha. Se ella estivesse em boa fé e quizesse ir, eu não poria obstaculo; mas aconselhar o que ella julga ser contra a sua Consciencia, dignidade e pudor de donzella christã, isso nunca farei.

Marido. - A nossa filha exagera as cousas. A Egreja Catholica não prohibe aos fieis o casamento civil para não ficarem prejudicados, contanto que estejam convencidos de que lá não casam.

Mulher. - E a nossa filha sabe disto; entende, porem, que a Egreja tolera o mal e não o approva: que como boa mãe não quer impor um jugo em demasia pesado a seus filhos, teme não encontrar bastante instrucção e brios nos fieis para reagirem.

Marido.- Em todo o caso devemos tirar a consequencia de que não é peccado, senão a Egreja o proibiria.

Mulher. - Não será peccado; apezar de que o que queres tu que eu responda, quando a nossa filha diz que aquelle recebo a vós no civil é uma mentira e mentira é peccado: a nossa filha é de consciencia delicada. Quanto a mim, fallo-te com franqueza, sinto-me possuida de orgulho, quando reparo na nobre attiude de nossa filha nessa questão.

Parece inspirada quando falla contra o casamento civil! O raio predileto com que o fulmina são as palavras de Pio IX “O casamento civil é um torpe e vil concubinato". Mamãe, me disse ella ainda esta manhã, não lhe parece cousa aviltante para o christão, não acha que offende o pudor de uma donzella ou mulher casada, proferir aquelle "recebo a vós" etc., formula nulla, falsa; absurda e ridicula.

As palavras sagradas que proferimos no templo do Senhor: as palavras tres vezes santas com que exprimimos um juramento religioso de eterno consorcio: as palavras sacramentaes com que adiante do altar da Nova Lei e da imagem do nosso adoravel Salvador celebramos um sacramento na presença do ministro de Deus, palavras de mystica sublimidade porque significam a união de Jesus com a Egreja Sua Esposa: essas palavras, mamãe, são rebaixadas, profanadas, arrastadas pela lama perante o delegado de um governo que se declarou atheu, e essa injuria será irrogada a Christo por tua filha catholica? Nunca, mamãe, prefiro morrer a repetir sacrilegamente a formula do sacramento do matrimonio! E dado que eu proferisse a formula, como poderia a minha consciencia aturar o cynis- 
mo revoltante do delegado do governo dizendo-me: - E eu vos reconheço e declaro legitimamente casados desde este momento - O senhor mente, eu diria indignada, apezar da boa educação que recebi, eu já estava casada legitimamente de viva fé. Eu applaudiria de todo o meu coração esse justissimo desabafo de indignação catholica por parte de minha filha, contando que houvesse um meio de induzil-a a que...

Mulher. - Usa de tua autoridade paterna: a nossa filha é obediente.

Marido. - Deus me livre de semelhante cousa. A justiça divina me castigaria se eu tal fizesse: - tambem prezo-me de ser catholico, declaro-me vencido pela grande fé de minha filha: louvo e admiro o seu procedimento, a dignidade e energia do seu caracter.

Mulher. - Viva imagem da tua é a alma de nossa filha: honradez e brio de caracter vos sobejam, felizes predisposições para a santa religião de Christo: pequenos seriamos na verdade, se tentassemos tomar de assalto uma fortaleza duplamente inexpugnavel pela natureza e pela graça. A nossa filha é uma santa: martyr seria se vivesse nos primeiros seculos do Christianismo.

Marido. - Tens razão, mulher: a consciencia catholica, a opinião publica do Brazil, do mundo inteiro dizem que a nossa filha está casada e bem casada. A idéa do partido catholico vinga, quando tivermos a nossa representação politica faremos valer a liberdade de consciencia tambem para nós os catholicos: a má fé dos nossos adversarios não se vence com discussão sobre principios, o que lhes amansa o furor revolucionario e os faz até ás nossas justas representações, é um avultado numero de votos no parlamento. ${ }^{45}$

A fala do casal está bem articulada para um cotidiano de raízes agrárias como era o da sociedade goiana, inclusive ao se evidenciar a importância da autoridade paterna, em razão de que o pai deveria fazer prevalecer a sua autoridade sobre a filha.

Assim, a Igreja manifestava posição contrária através de seus representantes que procuravam mostrar a não-validade do casamento civil e a importância do partido católico em Goiás. Este, fundado após a implantação da República, teve como objetivo fortalecer as propostas do clero conservador no Brasil.

No discurso do casal que representa a família católica, o que de fato se manifesta são as poucas qualidades de instrução e decisão das pessoas que freqüentavam a Igreja. Há por parte de quem produziu o diálogo, certamente falando em defesa da Igreja, um tratamento de desprezo para com o fiel, como se pode observar: "teme não encontrar bastante instrução e brios nos fieis para reagirem”. Torna-se explícito o desejo dos padres conservadores e o con- 
ceito que eles tinham dos fiéis, tidos como incapazes para repelir a nova lei do casamento.

Bispos ultramontanos tentaram normatizar a celebração do sacramento do matrimônio na cidade de Goiás, por meio de cartas pastorais enviadas aos vigários. Eles recomendavam a leitura de partes delas nas missas e nos eventos que se realizassem na paróquia, para que os fiéis pudessem inteirar-se da importância do sacramento do matrimônio.

A partir de 1889 houve adesão ao registro de casamento junto ao juiz de paz, o que nos faz acreditar que a ação dos padres conservadores não foi tão eficaz no sentido de combater o assentimento dos goianos à nupcialidade laica. Em 1890, quando se aprovou o projeto de casamento civil no Parlamento brasileiro, as pessoas deixaram de registrar o matrimônio religioso no Cartório Civil da cidade de Goiás, e passaram a solicitar a celebração do casamento pelo juiz de paz (ver ao lado Tabela 4).

Se cruzarmos os dados quantitativos da Tabela 4 com os da Tabela 1, observamos que nas décadas de 1880 e 1890 houve acréscimo no número de casamento sreligiosos, e também ao registro civil, que entrara em vigor com a Lei n. 1.829, de 1870, do Registro Civil dos Nascimentos, Casamentos e Óbitos, e depois ao casamento civil com o Decreto n. 181, de 1890. Neste sentido, nossa hipótese é de que os liberais exerciam sua influência junto às pessoas que procuraram regular suas relações conjugais junto ao juiz de paz.

É preciso salientar que o casamento religioso continuou crescendo até o final da década de 1880, momento em que o projeto do casamento civil tramitava no Parlamento, mas já estava em vigor a Lei n. 1.829, do Registro Civil dos Nascimentos, Casamentos e óbitos, aprovada em 9 de setembro de 1870. Os artigos da Constituição de 1891, sobre o casamento civil, não foram o marco inicial da secularização do matrimônio, e sim a consolidação do projeto liberal já discutido algumas décadas antes no Parlamento brasileiro, sendo o seu fruto inicial a lei acima referida. Foi a partir dessa década, ano de 1877, que as pessoas passaram a registrar os seus casamentos religiosos (católicos) no Cartório Civil.

Com a aprovação das propostas liberais no Parlamento brasileiro e o fortalecimento dos Bulhões, antigos liberais, no Estado, a Igreja goiana viu-se obrigada a trilhar outros caminhos. Em 1896, deu-se a transferência da sede da diocese da cidade de Goiás para Uberaba. Foi criada a diocese de Uberaba no ano de 1907, separando o território eclesiástico goiano do Triângulo Mineiro. Como sucessor do bispo D. Eduardo Duarte e Silva na diocese goiana, foi indicado o padre Prudêncio Gomes da Silva, para o período de 1908 1922. Este não era um ultramontano convicto tal qual o seu antecessor, e também o contexto histórico era outro, pois a proposta de modernização que ti- 
Tabela 4

Períodos de casamento civil, cidade de Goiás, 1889-1920

\begin{tabular}{|c|c|c|c|c|}
\hline Períodos & $\begin{array}{c}\mathrm{n}^{\mathbf{o}} \mathrm{de} \\
\text { termos } \\
\text { anotados }\end{array}$ & $\begin{array}{c}\mathrm{n}^{\mathrm{o}} \text { de casamentos } \\
\text { religiosos } \\
\text { no civil }\end{array}$ & $\begin{array}{c}\text { no de observações } \\
\text { de casados } \\
\text { no religioso }\end{array}$ & $\begin{array}{c}\mathrm{n}^{\mathbf{o}} \mathrm{de} \\
\text { casamentos }\end{array}$ \\
\hline $1877^{a}-1888$ & 16 & & & \\
\hline $1889-1890$ & & 20 & & 14 \\
\hline $1891-1892$ & & & & 54 \\
\hline $1893-1894$ & & 1 & 1 & 51 \\
\hline $1895-1896$ & & 1 & 2 & 73 \\
\hline $1897-1898$ & & & & 70 \\
\hline $1899-1900$ & & 1 & 1 & 64 \\
\hline $1901-1902$ & & & & 44 \\
\hline $1903-1904$ & & & & 36 \\
\hline $1905-1906$ & & & & 84 \\
\hline $1907-1908$ & & & & 75 \\
\hline $1909-1910$ & & & & 75 \\
\hline $1911-1912$ & & & & 74 \\
\hline $1913-1914$ & & & & 40 \\
\hline $1915-1916$ & & & & 68 \\
\hline $1917-1918$ & & & & 54 \\
\hline $1919-1920$ & & & 2 & 52 \\
\hline Total & 16 & 23 & 6 & 928 \\
\hline
\end{tabular}

Na documentação de registro de casamento civil da cidade de Goiás o primeiro "termo" - data de 11 de janeiro de 1877. A Lei n. 1829, que estabeleceu o Registro Civil dos Nascimentos, Casamentos e Óbitos, é de 9 de setembro de 1870.

Fontes: O primeiro livro s/n. são folhas ajuntadas e rubricadas; livros 1, 2, 3 e 4 de registros de casamento civil do Cartório de Registro Civil da cidade de Goiás. 
nha como pontos-chave o casamento civil e a separação entre Igreja e Estado estava definitivamente referendada pela Constituição de 1891. Ao novo bispo cabia cuidar bem do seu rebanho e aplicar à Igreja goiana apenas os projetos de ação social, restauração e recristianização dos pontífices Leão XIII e Pio X. D. Prudêncio Gomes da Silva mostrava ser um padre desinteressado de política. Tal fato corroboraria a história política de Goiás, que repousava em águas um pouco mais brandas até o reaparecimento da tempestuosa oligarquia dos Bulhões, que se deu em 10 de janeiro de 1909, quando Leopoldo de Bulhões e seus aliados fundaram o Partido Democrata em Goiás.

Assim, a atuação de D. Prudêncio Gomes da Silva estaria delimitada pelo domínio oligárquico, inicialmente dos Bulhões e depois dos Caiados no Estado. Maria Augusta de Morais mostra a trajetória política da oligarquia bulhônica. O influente José Leopoldo de Bulhões fora deputado federal e senador com destaque intelectual na comissão constitucional que o conduzira ao Ministério da Fazenda no governo de Rodrigues Alves. Ao finalizar o mandato de Rodrigues Alves, os fatos não acenavam para a recuperação do prestígio político dessa oligarquia no Estado, pois estando Leopoldo de Bulhões distante da capital, tudo indicava ter perdido a sua base de sustentação política. Mas os acontecimentos acabariam por apontar para outra direção. O governo do Esta142 do encontrava-se nas mãos de Xavier de Almeida, seu ferrenho opositor, que usava de artifícios e maestria para solapar as possibilidades de novos conchavos dos Bulhões. Tudo acenava para a impossibilidade de recuperação política de Leopoldo de Bulhões na esfera estadual, pois ao concluir o seu mandato no Ministério da Fazenda e ocupar a presidência do Banco do Brasil, estava pobre e no ostracismo e não poderia mais contar com a "fortuna do velho Inácio Soares de Bulhões [comerciante e capitalista] aplicada na educação dos 9 filhos, na manutenção de jornais, nas campanhas eleitorais [que se] diluira". ${ }^{46}$ Entretanto, no ostracismo, e residindo no Rio de Janeiro, Leopoldo de Bulhões habilmente conseguia manipular a política goiana através de seus aliados, o que prova que Xavier de Almeida, como esmerado político, não conseguira exterminar de vez o prestígio do clã bulhônico em Goiás.

No ano de 1908, a coligação de Leopoldo de Bulhões em oposição a Xavier de Almeida conseguira eleger 14 candidatos das 24 vagas para a Câmara Estadual, fato que animou José Leopoldo de Bulhões a visitar Goiás, de onde há 7 anos estava ausente, para buscar novas alianças. No seu retorno ao Rio de Janeiro, Leopoldo de Bulhões articularia e projetaria um plano revolucionário para ser posto em execução caso a oposição de José Xavier de Almeida vencesse as eleições.

Em 1909, deu-se o renascimento do mandonismo bulhônico articulado pela coligação republicana, que indicou Leopoldo de Bulhões como senador 
e para deputados Antônio Ramos Caiado, Marcelo Francisco da Silva (casado com a sobrinha de Bulhões) e o padre Trajano Baldíno. Em Goiás, sobretudo na capital, o clima era de inquietação. Os correligionários dos Bulhões arregimentavam homens e os agrupavam na fazenda da Quinta. O proprietário desta fazenda era Eugênio Rodrigues Jardim, que para atender o irmão Francisco Leopoldo, cunhado de Leopoldo de Bulhões, autorizara ser a sua fazenda um local de encontro para a possível derrubada de Xavier de Almeida. Os acontecimentos de abril e maio de 1909 indicavam que haveria um derramamento de sangue na capital; a historiadora Maria Augusta de Moraes ressalta que de fato houve, mas os documentos oficiais o omitiram.

No embate entre oligarquias que disputavam o poder, destacou-se como chefe político o coronel Antônio José Caiado, fazendeiro ligado ao centro republicano, mas desligado desde 1897 dos Bulhões, chegando a ocupar cargos no governo Xavier de Almeida. No entanto, o rompimento entre os Bulhões e Caiados propiciou a Antônio José Caiado ser um dos idealizadores do movimento em Goiás.

Em 14 de junho de 1909, com a morte de Afonso Penna, Leopoldo de Bulhões, como amigo de Nilo Peçanha, ocupou o Ministério da Fazenda no seu governo. O cunhado de Leopoldo de Bulhões, Urbano de Gouvêa, foi reconhecido presidente do Estado de Goiás. Isto ainda favoreceu o domínio bulhônico na política. À frente do comando político goiano estaria a oligarquia caiadista sob a liderança do coronel, fazendeiro e senador Antonio Ramos Caiado (Totó Brabeza), antes aliado dos Bulhões. O rompimento político entre ambos proporcionara à oligarquia caiadista o mandonismo local até a década de 1930. No momento em que Hermes da Fonseca entregou o comando político de Goiás aos Jardins-Caiados, Leopoldo de Bulhões viu-se obrigado a desligar-se da política goiana em nível estadual, mas continuou senador por Goiás até $1918{ }^{47}$

Ressaltamos a história política das primeiras décadas da República em Goiás, para que pudéssemos entender o contexto político em que o bispo D. Prudêncio Gomes da Silva administrou a Igreja, pois o cenário histórico-político da capital e sede da diocese não proporcionaria grandes realizações. Neste sentido, o cônego Trindade ressalta que D. Prudêncio, nos acontecimentos de 1909, teve uma "atitude calma e eficiente para evitar derramamento de sangue na família goiana”. ${ }^{48} \mathrm{O}$ não-envolvimento do bispo com a política favoreceu-lhe o apoio da oligarquia caiadista e facilitou-lhe efetivar a "estadualização" da Igreja em Goiás. Entre as realizações de D. Prudêncio destacaramse a reabertura do Seminário Santa Cruz, a reorganização do patrimônio da diocese na própria capital goiana, a fundação de alguns colégios em Pirenópolis, a ênfase nas devoções, o estabelecimento dos retiros, a organização dos 
arquivos paroquiais, a celebração dos sacramentos, com destaque ao matrimônio. Nas suas cartas pastorais chama atenção para a importância do recebimento do sacramento do matrimônio para não confundi-lo com o ato civil, cobrando dos padres a organização espiritual e administrativa das paróquias, bem como o ensinamento da doutrina católica. ${ }^{49}$

Sergio Miceli ressalta que, nas primeiras décadas da República, havia "metas de curto prazo" a serem cumpridas pela Igreja, e enfatiza que "o processo de estadualização a converteu em espaço de encenação das solenidades de legitimação e ostentação do poder oligárquico (...) com timbre eclesiástico (batizados, casamentos,...)". ${ }^{50} \mathrm{O}$ episcopado de D. Prudêncio Gomes da Silva apoiou essas metas e as cumpriu com a colaboração da oligarquia dos Caiados na diocese goiana, e sobretudo na cidade de Goiás.

\section{NOTAS}

* Reelaboração do texto apresentado no I Congreso Sudamericano de Historia, realizado de 20 a 22 de agosto de 2003, em Santa Cruz de la Sierra/Bolívia. Constitui parte da pesquisa que está sendo desenvolvida no doutoramento em História, com apoio financeiro da CAPES, orientada pelo Prof. Dr. Horacio Gutiérrez.

${ }^{1}$ AZZI, Riolando. Elementos para a história do catolicismo popular. Revista Eclesiástica Brasileira, vol. 36, fasc. 141, março de 1976, pp. 96-103.

${ }^{2}$ FRAGOSO, Hugo. A Igreja na formação do Estado imperial. In: BEOZZO, Oscar (coord.). História da Igreja no Brasil. Petrópolis: Vozes, 1992. Tomo II/2, p. 144.

${ }^{3}$ DORNAS, João Filho (1958), Antônio Carlos Villaça (1974), Riolando Azzi (1976), Roberto Romano (1979), David Gueiros Vieira (1980), José Oscar Beozzo (1980), Oscar de Figueiredo Lustosa (1980), Hugo Fragoso (1980), Augustin Wernet (1987), Ivan Aparecido Manoel (1996; 1998), Maria Aparecida Junqueira da Veiga Gaêta (1997), Ronaldo Ferreira Vaz (1997) e outros.

${ }^{4}$ VIEIRA, David Gueiros. O protestantismo, a maçonaria e a questão religiosa no Brasil. Brasília: UnB, 1980, pp. 32-3.

${ }^{5}$ MANOEL, Ivan Aparecido. O pêndulo da história - A filosofia da história do catolicismo conservador (1800-1960), Franca/SP, 1998. Tese de livre-docência — FHDSS, UNESP, p. 18.

${ }^{6}$ FRAGOSO, op., cit., p. 149.

${ }^{7}$ GAÊTA, Maria Aparecida J. da Veiga. Os percursos do ultramontanismo de D. Lino Deodato de Carvalho (1873-1874). São Paulo: 1991. Tese de doutorado em História. Faculdade de Filosofia, Letras e Ciências Humanas. USP, pp. 46-7.

${ }^{8}$ CARVALHO, José Murilo. Teatro de sombras. Rio de Janeiro: UFRJ, 1996, p. 147. É bem lembrada a abordagem de Carvalho, mas carece de pesquisas, uma vez que inexiste análise histórica sobre ela. 
${ }^{9}$ VILLAÇA, Antônio Carlos. História da questão religiosa no Brasil. Rio de Janeiro: Francisco Alves, 1974, pp. 1-2.

${ }^{10}$ SCAMPINI, José. A liberdade religiosa nas constituições brasileiras. Rio de Janeiro: Vozes, 1978 , p. 33.

${ }^{11}$ Idéias de modernização que não foram aplicadas em Goiás, uma vez que os Bulhões pouco ou nada fizeram para melhorar as condições econômicas do Estado.

${ }^{12}$ MORAES, Maria Augusta Sant'Anna. História de uma oligarquia em Goiás. Goiânia: Oriente, 1974, p. 100.

${ }^{13}$ Este foi “sagrado na Catedral de Belém do Pará por D. Macedo Costa em 1866". Revista dos bispos goianos. Aparecida/SP: Oficina Gráfica de Arte Sacra, 1948.

${ }^{14}$ D. Claudio José Gonçalves Ponce de Leão pertencia à Congregação da Missão, "por mercê de Deos e da Santa Sé apostólica, Bispo de Sant'Anna de Goyaz, do Conselho de Sua Magestade o Imperador”. Etc., etc. Carta pastoral. Bispo de Goyaz. O Synodo Diocesano — Goyaz. Typ. Perseverança de Tocantins \& Aranha, 1887.

${ }^{15}$ VAZ, Ronaldo Ferreira. Da separação Igreja-Estado em Goiás à nova cristandade (1891/1955). Goiânia: 1997. Dissertação de Mestrado em História das Sociedades Agrárias. UFG, 1997, p. 58.

${ }^{16}$ MORAES, op., cit., pp. 38-87.

${ }^{17}$ Idem, pp. 125, 162-63.

${ }^{18}$ Não há estudos sobre a atuação da maçonaria em Goiás.

${ }^{19}$ FARIA, Sheila de Castro. A Colônia em movimento: fortuna e família no cotidiano colonial. Rio de Janeiro: Nova Fronteira, 1998.

${ }^{20}$ MATTOS, Ilmar Rohloff de. O tempo saquarema: a formação do Estado imperial. 2 ed., São Paulo: Hucitec, 1990, p. 188.

${ }^{21}$ Nos livros de casamentos de 1860-1920, arquivados na Cúria da Diocese da cidade de Goiás, as anotações encontram-se incompletas, o que dá a entender que o escrivão da paróquia não as fazia de imediato à celebração do matrimônio.

${ }^{22}$ Livro n. 6 de registro de casamento da paróquia de S. Anna, 1901, p. 82.

${ }^{23}$ Revista A Cruz, 3 de março de 1890, nº 4, p. 26.

${ }^{24}$ TELES, José Mendonça. Fronteira. Goiânia: Oriente, 1977, p. 108.

${ }^{25}$ SILVA, José Trindade da Fonseca (cônego). Lugares e pessoas - Subsídios eclesiásticos para a história de Goiás - 1ํv.. Escolas Salesianas, SP, 1948, p. 292.

${ }^{26}$ MACFARLANE, Alan. História do casamento e do amor: Inglaterra, 1300-1840. São Paulo: Companhia das Letras, 1990, p. 131.

${ }^{27}$ Em alguns registros de casamento religioso não consta a idade dos nubentes.

${ }^{28}$ MORAES, op. cit., pp. 40-3.

${ }^{29}$ JAYME, Jarbas. Famílias Pirenopolinas. V. I e III. Campinas/GO: Rio Branco, 1973, pp. 57-66; 163.

${ }^{30}$ NUNES, Heliane Prudente. História da família no Brasil e em Goiás: tendências e deba- 
tes. In: Goiás: Identidade, paisagem e tradição. CHAUL, Nasr Fayad; RIBEIRO, Paulo Rodrigues (orgs.). Goiânia: UCG, 2001, p. 69.

${ }^{31}$ Nos títulos LXII — LXXVI. São Paulo: Typograhia 2 de Dezembro, 1853, pp. 107-134.

${ }^{32}$ SILVA, Maria Beatriz Nizza. Sistema de casamento no Brasil colonial. São Paulo: TAQ, 1984, pp. 132-33.

${ }^{33}$ NUNES, op., cit., p. 66.

${ }^{34}$ SAMARA, Eni de Mesquita. Estratégias matrimoniais no Brasil do século XIX. Revista Brasileira de História, 1988, São Paulo, v. 8, n. 15, 1987/1988, p. 96.

${ }^{35}$ Nosso recorte cronológico é posterior à estada de viajantes estrangeiros à capital goiana, mas os analisamos para entender o que eles disseram sobre os costumes da população, notadamente no que refere à nupcialidade. Os escritos dos viajante Saint-Hilaire e Joahan Emanuel Pohl não oferecem respostas satisfatórias para investigar uma temática tão rica como a do matrimônio e concubinato na cidade de Goiás.

${ }^{36}$ SAINT-HILAIRE, Auguste de. Viagem à província de Goiás. Trad. Regina Regis Junqueira. Belo Horizonte: Editora Itatiaia; São Paulo: USP, 1975, p. 53.

${ }^{37}$ Joaquim Vicente de Azevedo, no ano de 1876, era cônego e governador do bispado goiano. Foi também diretor do "lyceu" na cidade de Goiás. Ocupou funções que revelavam posição, prestígio social e poder.

${ }^{38}$ Guias das pessoas sepultadas no cemitério público desta cidade, nomes de documentos do hospital Pedro de Alcântara, arquivados no Arquivo Frei Simão.

${ }^{39}$ LEWCOWICZ, Ida. A fragilidade do celibato. In: LIMA, Lana Lage (org.). Mulheres, adúlteros e padres: história e moral na sociedade. Rio de Janeiro: Dois pontos, 1987, p. 62.

${ }^{40}$ FRAGOSO, op. cit., p. 193.

${ }^{41}$ MORAES, op., cit., p. 55.

${ }^{42}$ Revista religiosa fundada em Goiás, no ano de 1890, por frei Gil Vilanova, mas teve vida efêmera, deixando de circular no ano seguinte (TELES, 1989, p. 38).

${ }^{43}$ Revista A Cruz. Goyaz, n. 3, 19 de fevereiro de 1890, pp. 18 - 27.

${ }^{44}$ Idem, p. 18.

${ }^{45}$ Idem, p. 111.

${ }^{46}$ MORAIS, op., cit., p. 250.

${ }^{47}$ Idem.

${ }^{48}$ SILVA, José Trindade da Fonseca (cônego). Lugares e pessoas (subsídios eclesiásticos para a história de Goiás). 1. v. Escolas Salesianas, SP, 1948, p. 371.

${ }^{49}$ SANTOS, Miguel Archângelo Nogueira dos. Missionários Redentoristas alemães em Goiás, uma participação nos movimentos de reforma e de restauração. São Paulo: 1984. Tese de doutoramento. USP.

${ }^{50}$ MICELI, Sergio. A elite eclesiástica brasileira. Rio de Janeiro: Bertrand Brasil, 1988, p. 22.

Artigo recebido em 1/2003. Aprovado em 10/2003. 